\title{
Suicide attempt, impulsivity, and exposure to trauma in college students
}

Sidnei B. Lira, ${ }^{1 \star}$ Flávia Vieira, ${ }^{1,2 \star}$ Diogo E. Cavalcanti, ${ }^{3,4 \star}$ Breno Souza-Marques, ${ }^{1,2}$ Liana R. Netto, ${ }^{1}$ Fernanda S. Correia-Melo, ${ }^{1,2}$ Gustavo C. Leal, ${ }^{1,2}$ Juliana L. Pereira, ${ }^{1}$ Lene L. Santos, ${ }^{1}$ Gisela M. Guedes, ${ }^{1}$ Carlos A. Teles, ${ }^{5}$ Taiane de A. Cardoso, ${ }^{6}$ Ângela Miranda-Scippa, ${ }^{1}$ Flavio Kapczinski, ${ }^{6}$ Acioly L.T. Lacerda, ${ }^{7}$ Karestan C. Koenen, ${ }^{8}$ Gustavo Turecki, ${ }^{9}$ Lucas C. Quarantini ${ }^{1,2}$ iD

${ }^{1}$ Programa de Pós-graduação em Medicina e Saúde, Faculdade de Medicina da Bahia, Universidade Federal da Bahia, Salvador, BA, Brazil. ${ }^{2}$ Laboratório de Neuropsicofarmacologia, Serviço de Psiquiatria, Hospital Universitário Professor Edgard Santos, Universidade Federal da Bahia, Salvador, BA, Brazil. ${ }^{3}$ Centro Universitário Social da Bahia, Salvador, BA, Brazil. ${ }^{4}$ Centro Universitário Jorge Amado, Salvador, BA, Brazil. ${ }^{5}$ Centro de Pesquisa Gonçalo Moniz, Fundação Oswaldo Cruz, Salvador, BA, Brazil. ${ }^{6}$ Department of Psychiatry and Behavioural Neurosciences, McMaster University, Hamilton, ON, Canada. ${ }^{7}$ Laboratório Interdisciplinar de Neurociências Clínicas, Universidade Federal de São Paulo, São Paulo, SP, Brazil. ${ }^{8}$ Department of Epidemiology, Harvard T. H. Chan School of Public Health, Boston, MA, USA. ${ }^{9}$ McGill Group for Suicide Studies, Douglas Mental Health University Institute \& Department of Psychiatry, McGill University, Montreal, Canada.

* These authors contributed equally to this article.

Objectives: Past suicide attempt (SA) is one of the most important risk factors for suicide death. An ideation-to-action framework posits that impulsivity, potentially traumatic events, and mental disorders also play a role in increasing suicide risk. This study aimed to assess the association between trait impulsivity, lifetime exposure to trauma, and post-traumatic stress disorder (PTSD) with $\mathrm{SA}$ in a sample of Brazilian college students.

Methods: A total of 2,137 participants filled self-reported questionnaires consisting of a sociodemographic and clinical questionnaire, Trauma History Questionnaire, Post-Traumatic Stress Disorder Checklist - Civilian version, and Barratt Impulsiveness Scale.

Results: Our findings suggest that trait impulsivity may be interpreted as exerting a distal effect on SA, even in the presence of other variables - such as trauma history, psychological neglect, and PTSD which also increase the odds of SA. High and medium levels of impulsivity, history of trauma, and PTSD increased the likelihood of SA.

Conclusions: Intervention strategies to prevent SA may target trait impulsivity and exposure to traumatic experiences.

Keywords: Suicide attempt; suicide; impulsivity; trauma and stressor related disorders; posttraumatic stress disorder

\section{Introduction}

Suicide is a global health problem that accounts for nearly $2 \%$ of all worldwide deaths annually and figures as one of the five leading causes of mortality in individuals aged between 10 to 24 years old. ${ }^{1}$ Suicide attempts (SA) are even more common than mortality by suicide. SA is included on the spectrum of suicidal behavior, a broad construct that also involves suicidal ideation (SI), planning for suicide, and suicide itself. A history of SA is the most important risk factor for completed suicide in the general population, ${ }^{2}$ and such association is explained by theoretical underpinnings of the ideation-to-action framework.

Correspondence: Lucas C. Quarantini, Universidade Federal da Bahia, Hospital Universitário Professor Edgard Santos, Serviço de Psiquiatria, R. Doutor Augusto Viana, $3^{\circ}$ andar, CEP 40110-060, Salvador, BA, Brazil.

E-mail: Icq@ufba.br

Submitted Aug 10 2021, accepted Nov 02 2021, Epub Mar 072022.
The ideation-to-action framework is a major breakthrough in the study of suicide, with theoretical and empirical implications that have been consistently backed by evidence. ${ }^{3}$ Of note, it proposes some of the factors commonly associated with suicide will specifically predict $\mathrm{SI}$, while others may facilitate the transition from ideation to attempt. The Three-step Theory (3ST), one of the newer theories of suicidal behavior within the ideation-toaction framework, postulates three crucial steps: pain and hopelessness are necessary for the development of suicidal thoughts; if pain exceeds connectedness, these thoughts may settle and escalate; and high levels of SI will only give way to an attempt if the individual has the capability for it. ${ }^{4,5}$

How to cite this article: Lira SB, Vieira F, Cavalcanti DE, SouzaMarques B, Netto LR, Correia-Melo FS, et al. Suicide attempt, impulsivity, and exposure to trauma in college students. Braz J Psychiatry. 2022;44:279-288. http://dx.doi.org/10.1590/1516-44462021-2175 
Impulsivity was previously considered as a factor that should account for an individual's chances of death by suicide, and has been included in clinical guidelines. ${ }^{6,7}$ Counterintuitively, longitudinal studies have found weak or no associations between trait-impulsivity and SAs. ${ }^{3}$ More specifically, individuals with $\mathrm{SI}$ and individuals who attempted suicide were found to have similar levels of impulsivity, suggesting that impulsivity is not an immediate predictor of SAs. ${ }^{8,9}$ A different perspective, however, proposes another line of reasoning: first, impulsive or unplanned attempts are highly uncommon; as a consequence, impulsivity may be viewed to exert its effects as a distal factor. ${ }^{10}$ In this perspective, trait impulsivity may act longitudinally by increasing one's chances to come across painful and provocative events, ${ }^{10}$ which, as predicted by the 3ST model, will contribute to raise one's suicide capability.

According to the 3ST model, suicide capability may be understood through dispositional, practical, and acquired components, the latter being hypothesized to arise from exposure and habituation to provocative or painful experiences. ${ }^{4}$ In line with this, the acquired component of suicide capability was higher in participants with a history of SAs than in those with a history of SI only, and the association with history of SA remained significant even after adjusting for current $\mathrm{SI}^{4,11}$ These experiences can take a variety of forms, including non-suicidal selfinjury, previous SAs, and exposure to traumatic or threatening events. ${ }^{12}$

Adverse childhood experiences, such as sexual, physical, and emotional abuse, as well as physical neglect, have been associated with $\mathrm{SA}^{13}$ and are some of the ways in which an individual may be exposed to painful and provocative events. The number of adverse experiences in this period has been associated with a higher likelihood to attempt suicide throughout the lifespan. ${ }^{14}$ Accordingly, adults with depression and a history of childhood abuse were found to be more likely to have attempted suicide than those who did not report such history. ${ }^{15}$ Beyond childhood adversities, lifetime traumatic experiences were found to both increase one's likelihood to be hospitalized following a SA rather than ideation, ${ }^{16}$ and to increase acquired capability. ${ }^{17}$ In line with this evidence, a recent systematic review demonstrated a significant association between traumatic life events and suicide risk in college students, with medium-to-large effect sizes. ${ }^{18}$

Reexperiencing symptoms of post-traumatic stress disorder (PTSD), such as mental rehearsal of painful and provocative experiences, was positively correlated to the acquired capability for suicide, even when controlling for sex and general mental health, in a sample of military personnel examined for traumatic brain injury. ${ }^{19}$ Another study also found that PTSD diagnosis, which requires exposure to one or more traumatic events involving actual or threatened death, sexual violence, or serious injury to self or others, was associated with increased acquired suicide capability among adult outpatients. ${ }^{20}$ Relatedly, disorders characterized by impulsive-control deficits and severe anxiety/agitation, including PTSD, predict the transition from suicidal thoughts to suicide plans or SA among individuals with $\mathrm{SI}^{21}$
The relationship between impulsivity and capability for suicide is hypothesized to be mediated by painful and provocative events, with impulsivity being considered a distal risk factor for suicidal behavior. ${ }^{10}$ Jordan et al. ${ }^{22}$ have shown that painful and provocative events were a significant predictor of suicide intent and supported the hypothesis of indirect relationship between impulsivity and suicide intent, suggesting that the relationship between impulsivity and intent occurs through exposure to painful and provocative events.

This study aims to assess the level of association between trait impulsivity, acquired capability (measured by lifetime exposure to traumatic events), and SA in Brazilian college students. We hypothesized that impulsivity would act as a distal factor for SAs by exacerbating acquired capability. For this purpose, we investigate: 1) whether a history of traumatic experiences and PTSD are on the path between impulsivity and SA; and 2) whether a history of traumatic experiences and PTSD increases the odds of SA in a nonclinical sample.

\section{Methods}

\section{Study design, sampling, and participants}

This is a cross-sectional study including students of seven colleges in Northeastern Brazil from April to July of 2011. The institutions were selected by convenience criteria, including three public and four private colleges located in urban areas of the states of Bahia and Paraiba. We made efforts to capture a broad profile of Northeastern college students by selecting colleges with high student migration rates, given that some students move to attend university outside their home cities. ${ }^{23}$

The Northeastern region of Brazil, which is one of the most violent areas nationally, ${ }^{24}$ encompasses nine of the 26 states of the country and has become the second region with the highest concentration of undergraduate students, according to census data on college education. ${ }^{25}$

The inclusion criteria for participants were: 1) age 18 years or older; 2) being a student from the aforementioned colleges; 3 ) being enrolled in either the first or the last semester of any undergraduate program; and 4) regularly attending classes.

\section{Measures}

The protocol consisted of self-reported instruments, all of which were previously adapted to Brazilian Portuguese. College students attending class in person were asked to participate in the study, and those that accepted were instructed to complete the following:

a) Sociodemographic and clinical questionnaire, including three questions about suicide: Have you ever thought about killing yourself? Have you made a suicide attempt? If yes, how many times have you attempted suicide? To explore substance use patterns (first use, current use, frequency, quantity, and interpersonal consequences), we included five questions about alcohol, tobacco, and illicit psychoactive substance consumption. 
b) To assess the history of psychological neglect, we used a survey based on the work of Azevedo \& Guerra, ${ }^{26}$ comprising three questions: 1) Has someone spoken to you in a way that made you feel neglected or humiliated?; 2) Has someone required you to perform tasks that you thought were beyond your ability to perform?; 3) Has someone threatened you saying he/she could abandon you or kill you?

c) The Trauma History Questionnaire $(T H Q)^{27}$ was administered to examine exposure to traumatic experiences, assessing 23 potentially traumatic life events using dichotomous questions. Subjects were also asked about the frequency and age at the time of each endorsed event. One question allows individuals to describe other personal experiences not included in the other items.

d) The Post-Traumatic Stress Disorder Checklist - Civilian version $(P C L-C)^{28}$ was used to assess symptoms of PTSD, based on the DSM-IV-TR ${ }^{29}$ criteria. Considering the worst trauma reported in the THQ, the participants were instructed to answer all 17 items and rate each of them on a five-point scale (ranging from 1, not at all, to 5, extremely), reporting how much he/she had been bothered by the listed symptoms in the last month. Based on Adkins et al., ${ }^{30}$ who compared the psychometric properties of seven self-reported measures of PTSD in a similar setting (civilian trauma-exposed college students), the adopted cutoff point for the PCL-C was $\geqslant 45$. For more information about PTSD diagnosis, see Netto et al. ${ }^{31}$

e) The Barratt Impulsiveness Scale (BIS-11) ${ }^{32}$ was used to assess impulsive behavior, distributed across 30 items scored on a Likert-type scale (ranging from 1, rarely/never, to 4 , almost always/always). The BIS-11 total score was categorized into meaningful classes using cutoff scores: $<52$, low; 52-71, normal; and $>71$, high. $^{33}$

\section{Hierarchical conceptual model}

The hierarchical conceptual model explored two possibilities: impulsivity as directly associated with SA or indirectly associated with $S A$ by raising the odds of developing PTSD. A theoretical framework was structured with variables associated with $S A$, classifying them into hierarchical blocks (Figure 1), ${ }^{34,35}$ in which an earlier factor affects a latter one, but not vice versa. If a latter variable diminishes an earlier variable's association with $\mathrm{SA}$, this latter variable can be thought of as a partial or total mediator.

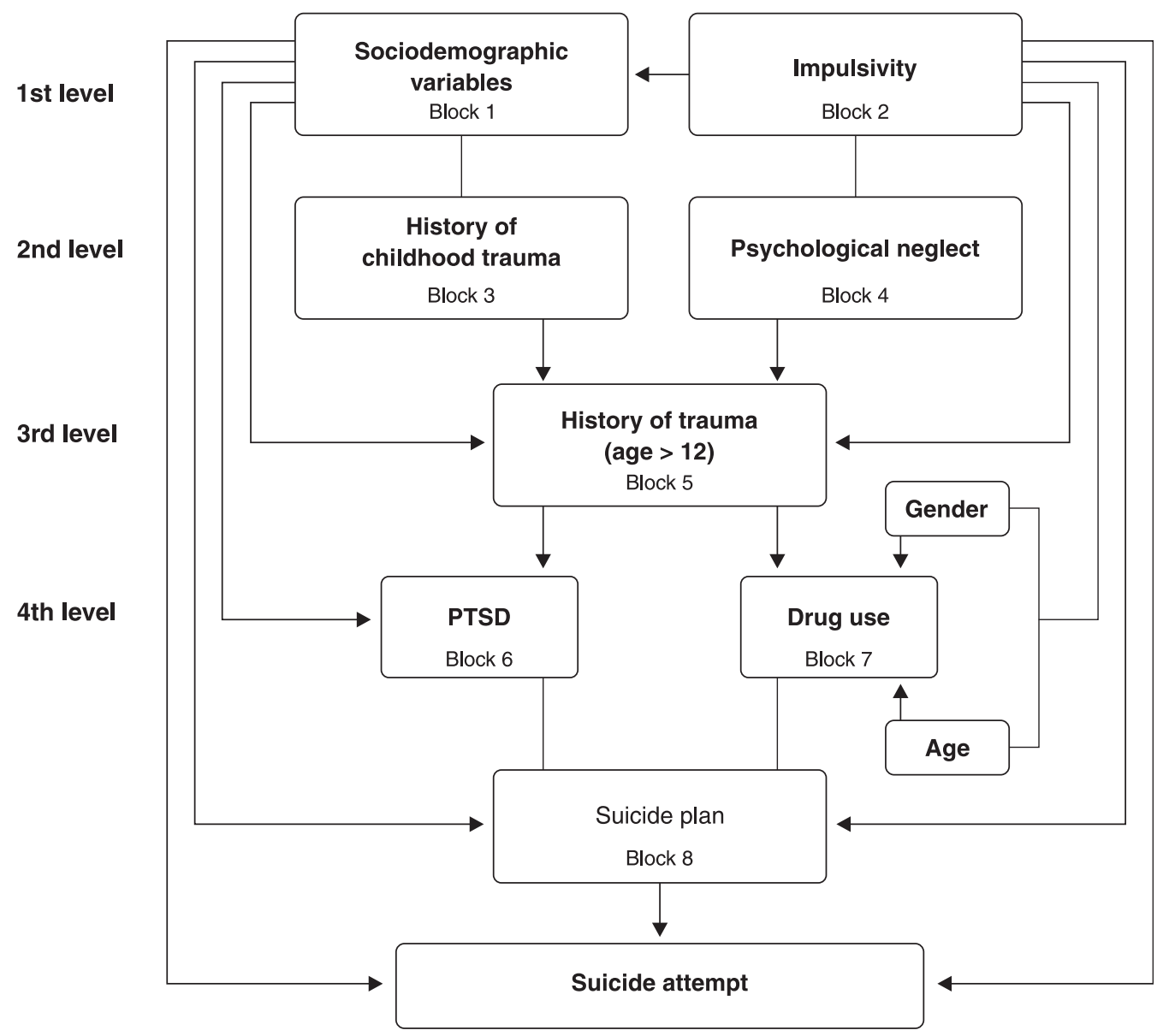

Figure 1 Hierarchical conceptual model of risk factors for suicide attempt in college students from Northeastern Brazil impulsivity as a first-level factor. PTSD = post-traumatic stress disorder. 
Sociodemographic variables and impulsivity (blocks 1 and 2) were inserted in the first level of the hierarchy (level 1), so we could assess if their possible effects on SA would remain significant following the inclusion of the subsequent blocks of variables. History of trauma (age $\leqslant 12$ ) and psychological neglect (blocks 3 and 4) were the intermediate factors (level 2), along with a history of trauma (age $>12$ - block 5). PTSD and drug use (blocks 6 and 7 ) were the latter factors (level 4). The constructed model respected the chronology of relations between the variables and the outcomes.

Impulsivity was also inserted later in the hierarchy as a test of model validity, while sociodemographic variables (block 1) were maintained on the first level (level 1). History of trauma (age $\leqslant 12$ ) and psychological neglect (blocks 2 and 3) were the intermediate factors (level 2), along with a history of trauma (age $>12$ - block 4). PTSD, impulsivity, and drug use (blocks 5, 6, and 7) were inserted as the latter factors (level 4) (Figure 2).

\section{Statistical analysis}

The statistical analysis consisted of three stages. The first stage was a univariate analysis of the sociodemographic and clinical characteristics of the sample to determine their relative and absolute frequency. In the second stage, we did a bivariate analysis ( $\chi^{2}$ or Fisher test) to measure the association between clinical and sociodemographic variables and the occurrence of SA, expressed by odds ratio (OR).

Finally, the third stage consisted of multivariate analysis. For this purpose, we used an effect-decomposition strategy, similar to an approach suggested by other authors. ${ }^{35,36}$ We fitted a sequence of multivariate logistic regression models by including step-by-step blocks (groups of variables) of potential risk factors, according to a predefined hierarchy. A sequential process allows for the entry of predictor variables in accordance with a theoretical framework and with the available literature. ${ }^{37}$ This is especially useful given our objective to assess impulsivity, here conceptualized as an individual trait, as a factor that may exert an effect on SA after controlling for other relevant variables. We used a backward elimination procedure for each block to identify significant risk factors $(p<0.05)$.

Following our conceptual framework (Figure 1), we fitted four logistic regression models. Model A (blocks 1 and 2) sought to estimate the overall effect of socioeconomic

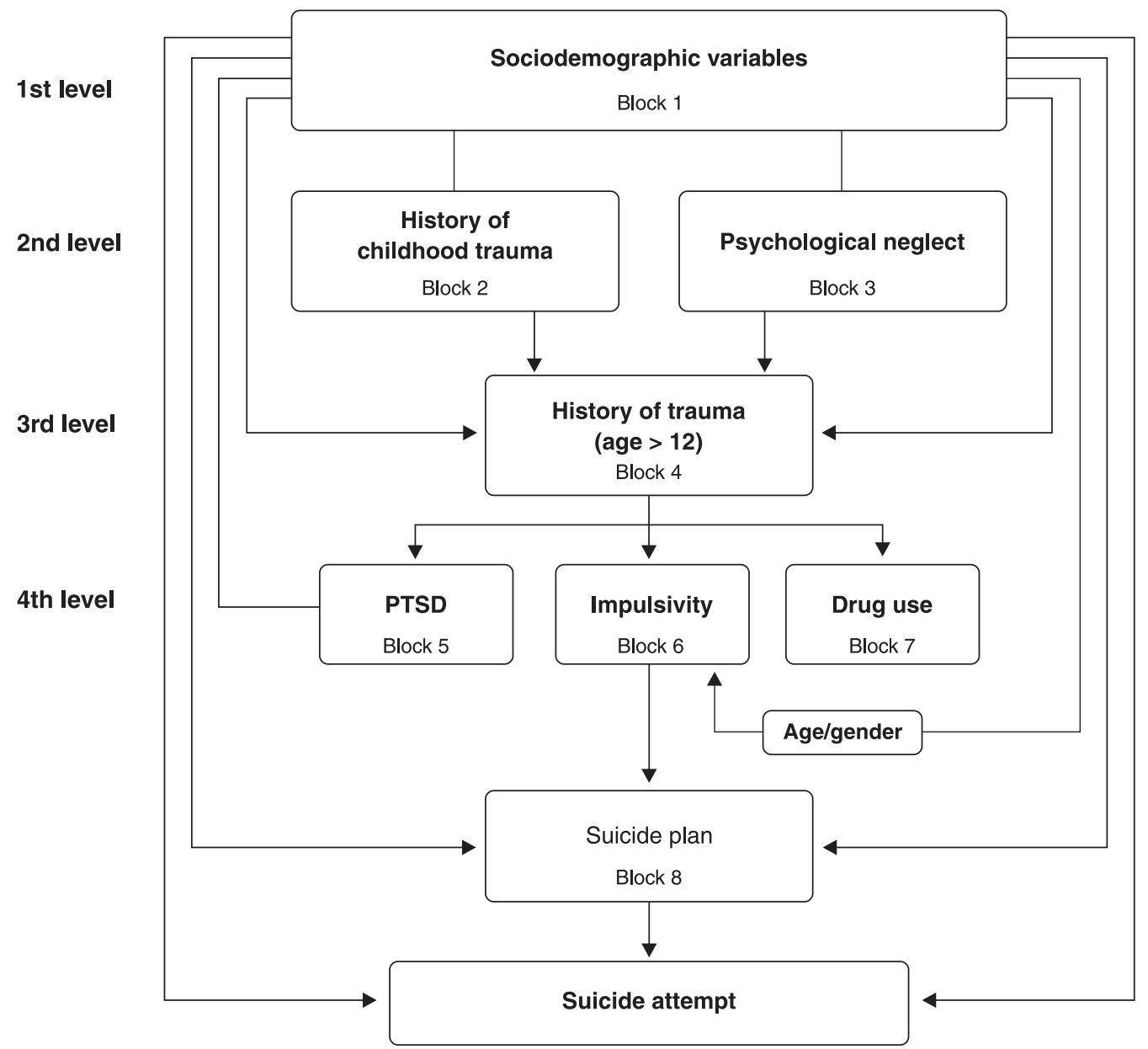

Figure 2 Hierarchical conceptual model of risk factors for suicide attempt in college students from the Northeastern, Brazil impulsivity as a latter factor. PTSD = post-traumatic stress disorder. 
status and impulsivity. Model $B$ also included variables from blocks 3 and 4 and sought to estimate the effect of socioeconomic status and impulsivity not mediated through blocks 3 and 4 , as well as to estimate the overall effect of variables in blocks 3 and 4 . Model C (variables of blocks 1 , $2,3,4$, and 5) sought to estimate the effects of socioeconomic status and impulsivity not mediated through blocks 3,4 , and 5 ; the effect of block 3 and 4 not mediated by block 5; and the overall effect of variables in block 5 . Model D (variables of blocks 1, 2, 3, 4, 5, and 6) sought to estimate the effects of socioeconomic status and impulsivity not mediated through blocks $3,4,5$, and 6 ; the effect of blocks 3 and 4 not mediated by blocks 5 and 6 ; the effect of block 5 not mediated by block 6 ; and the overall effect of variables in block 6 . Model $\mathrm{E}$ (variables of blocks 1, 2, 3, 4, 5,6 , and 7 ) sought to estimate the effect of socioeconomic status and impulsivity not mediated by blocks $3,4,5,6$, and 7 ; the effect of blocks 3 and 4 not mediated by blocks 5,6 and 7; the effect of block 5 not mediated by blocks 6 and 7; and the overall effect of variables in blocks 6 and 7 .

We used a hierarchical counter-model (Figure 2) to analyze the role of impulsivity as an antecedent of SA. This variable was displaced to the last block of the hierarchical analysis, keeping the other variables in their blocks and levels. We found that impulsivity was not a mediator of the other variables included in the previous levels. The model of this study seems to be more viable when it inserts impulsivity as a first-level factor.

\section{Ethics approval}

This study was approved by the local ethics committees (Bahia: COM/UFBA, opinion \#227/2010; Paraíba: Faculdade Santa Maria, 17-02-2011), and was carried out in accordance with the provisions of the Declaration of Helsinki. Participation was voluntary, and all participants provided written informed consent before enrollment in the study.

\section{Results}

Of 2,589 eligible students, 2,137 were included in the study (82.5\%), of whom $167(7.8 \%)$ reported having had at least one SA in their lifetime. Most of the participants with a history of SA were single $(78.2 \%)$, female $(77.6 \%)$, and from income categories C, D, and E $(60.1 \%)$ (Table 1).

Bivariate analysis was performed among independent variables and the SA outcome (Table 2). We found an association between impulsivity and history of $S A(p<$ 0.001 ). Among subjects with high levels of impulsivity, as defined by BIS-11 scores $>71,12.3 \%$ had a history of $\mathrm{SA}$; of those with medium levels of impulsivity, $6.1 \%$ had a history of SA; and of those with low levels of impulsivity, only $4.3 \%$ had a prior SA. History of trauma involving physical/sexual experiences, both before and after 12 years old, was associated with SA $(p<0.001)$, as was psychological neglect $(p<0.001)$. PTSD was also associated with SA ( $<<0.001) ; 21.8 \%$ of college students with PTSD attempted suicide at least once, compared with $5.6 \%$ of those without PTSD $(p<0.001)$. Finally, regarding drug usage, frequencies of SA were higher in individuals who used two or more drugs (12\%), followed by those who used one drug (8.3\%) and those who never used any drugs (5.9\%).

The results of the multivariate hierarchical analysis are presented in Table 3. We found that subjects who were single had a $44 \%$ greater likelihood of attempting suicide than married subjects. This probability did not hold significance as the hierarchical analysis accounted for more blocks. Higher family income had an inverse association with SA in Model A (categories A + B and $C)$, and categories $A+B$ remained associated with a lower OR in Model B. High and medium levels of impulsivity increased the likelihood of SA (OR 7.35; $95 \%$ confidence interval $[95 \% \mathrm{Cl}] 3.43-15.76$ and OR $2.74 ; 95 \% \mathrm{Cl} 1.32-5.69$, respectively). As hypothesized, when other variables were included in the model, such as

Table 1 Sociodemographic characteristics of college students according to history of suicide attempt, Northeastern Brazil

\begin{tabular}{|c|c|c|c|c|}
\hline \multirow[b]{2}{*}{ Sociodemographic variables } & \multirow[b]{2}{*}{ Total $(n=2,137)$} & \multicolumn{2}{|c|}{ Suicide attempt } & \multirow[b]{2}{*}{$p$-value } \\
\hline & & No $(n=1,970)$ & Yes $(n=167)$ & \\
\hline $\begin{array}{l}\text { Female sex } \\
\text { Age, years }\end{array}$ & $1,360(65.9)$ & $1,235(64.9)$ & $125(77.6)$ & $\begin{array}{l}0.001 \\
0.887\end{array}$ \\
\hline $\begin{array}{l}\leqslant 22 \\
>22\end{array}$ & $\begin{array}{l}1,099(51.4) \\
1,038(48.5)\end{array}$ & $\begin{array}{c}1,014(51.4) \\
956(48.6)\end{array}$ & $\begin{array}{l}85(50.9) \\
82(49.1)\end{array}$ & \\
\hline $\begin{array}{l}\text { Marital status } \\
\text { Single } \\
\text { Married } \\
\text { Divorced } \\
\text { Widowed }\end{array}$ & $\begin{array}{c}1,728(82.8) \\
328(15.7) \\
27(1.3) \\
5(0.2)\end{array}$ & $\begin{array}{c}1,599(83.1) \\
297(15.4) \\
23(1.2) \\
4(0.2)\end{array}$ & $\begin{array}{c}129(78.2) \\
31(18.7) \\
4(2.4) \\
1(0.6)\end{array}$ & 0.230 \\
\hline $\begin{array}{l}\text { Socioeconomic class } \\
A+B \\
C \\
D+E\end{array}$ & $\begin{array}{l}994(48.0) \\
692(33.4) \\
384(18.6)\end{array}$ & $\begin{array}{l}929(48.7) \\
638(33.4) \\
340(17.8)\end{array}$ & $\begin{array}{l}65(39.8) \\
54(33.1) \\
44(27.0)\end{array}$ & 0.010 \\
\hline
\end{tabular}

Data presented as $\mathrm{n}(\%)$.

The Brazilian Economic Classification Criterion is based on annual household income: Class A + B $\geqslant \$ 25.356,00 / \$ 25.356,00>$ Class C $\geqslant$ $\$ 5.136,00 / \$ 5.136,00>$ Class $D+E \geqslant \$ 2.208,00$ (in 2011 U.S. dollars).

$\chi^{2}$ or Fisher test. 
Table 2 Bivariate analysis among independent variables and the outcome of interest (suicide attempt) among college students in Northeastern Brazil $(n=2,137)$

\begin{tabular}{|c|c|c|c|}
\hline \multirow[b]{2}{*}{ Variables } & \multicolumn{2}{|c|}{ Suicide attempt } & \multirow[b]{2}{*}{$p$-value } \\
\hline & No $(n=1,970)$ & Yes $(n=167)$ & \\
\hline $\begin{array}{l}\text { Impulsivity } \\
\text { High } \\
\text { Medium } \\
\text { Low }\end{array}$ & $\begin{array}{l}651(87.3) \\
644(93.9) \\
675(95.7)\end{array}$ & $\begin{array}{l}95(12.3) \\
42(6.1) \\
30(4.3)\end{array}$ & $<0.001$ \\
\hline \multicolumn{4}{|l|}{ History of trauma (age $\leqslant 12$ ) } \\
\hline $\begin{array}{l}\text { Crime-related events } \\
\text { Yes } \\
\text { No }\end{array}$ & $\begin{array}{c}232(90.3) \\
1738(92.4)\end{array}$ & $\begin{array}{c}25(9.7) \\
142(7.6)\end{array}$ & 0.223 \\
\hline $\begin{array}{l}\text { Physical/sexual experiences } \\
\text { Yes } \\
\text { No }\end{array}$ & $\begin{array}{c}189(84.0) \\
1781(93.1)\end{array}$ & $\begin{array}{l}36(16.0) \\
131(6.9)\end{array}$ & $<0.001$ \\
\hline $\begin{array}{l}\text { Psychological neglect } \\
\text { Yes } \\
\text { No }\end{array}$ & $\begin{array}{c}312(85.0) \\
1658(93.7)\end{array}$ & $\begin{array}{l}55(15.0) \\
112(6.3)\end{array}$ & $<0.001$ \\
\hline \multicolumn{4}{|l|}{ History of trauma (age $>12$ ) } \\
\hline $\begin{array}{l}\text { Crime-related events } \\
\text { Yes } \\
\text { No }\end{array}$ & $\begin{array}{c}956(91.6) \\
1014(92.8)\end{array}$ & $\begin{array}{l}88(8.4) \\
79(7.2)\end{array}$ & 0.301 \\
\hline $\begin{array}{l}\text { General disaster } \\
\text { Yes } \\
\text { No }\end{array}$ & $\begin{array}{c}570(93.9) \\
1400(91.5)\end{array}$ & $\begin{array}{c}37(6.1) \\
130(8.5)\end{array}$ & 0.062 \\
\hline $\begin{array}{l}\text { Physical/sexual experiences } \\
\text { Yes } \\
\text { No }\end{array}$ & $\begin{array}{c}175(79.2) \\
1795(93.7)\end{array}$ & $\begin{array}{l}46(20.8) \\
121(6.3)\end{array}$ & $<0.001$ \\
\hline $\begin{array}{l}\text { PTSD } \\
\text { Yes } \\
\text { No }\end{array}$ & $\begin{array}{c}233(78.2) \\
1737(94.4)\end{array}$ & $\begin{array}{l}65(21.8) \\
102(5.6)\end{array}$ & $<0.001$ \\
\hline $\begin{array}{l}\text { Drug use } \\
\text { Never } \\
\text { One drug } \\
\text { Two or more drugs }\end{array}$ & $\begin{array}{l}804(94.1) \\
917(91.7) \\
249(88.0)\end{array}$ & $\begin{array}{c}50(5.9) \\
83(8.3) \\
34(12.0)\end{array}$ & 0.003 \\
\hline
\end{tabular}

Data presented as $\mathrm{n}(\%)$.

PTSD = post-traumatic stress disorder $(p \leqslant 0.05)$.

To explore different levels of impulsivity in the groups, Barratt Impulsiveness Scale (BIS-11) measures were explored through tertiles.

trauma history, psychological neglect, and PTSD, we observed a decrease in the OR of impulsivity.

A history of physical/sexual traumatic experiences before and after 12 years old - was associated with SA, with ORs decreasing as more blocks were considered. Physical/sexual traumatic experiences before 12 years old did not hold significance in Models $D$ and $E$ when PTSD and drug use variables were included in the model. Having experienced psychological neglect more than doubled the odds of SA, decreasing to an OR 1.79 $(95 \% \mathrm{Cl} 1.24-2.58)$ in Model $\mathrm{E}$, when all variables were included. PTSD increased the odds of SA (OR 2.80; 95\% Cl 1.92-4.08) in Model D, decreasing slightly when drug use was included in Block 7.

\section{Discussion}

The results of the present study suggest an association of trait impulsivity, lifetime exposure to traumatic events (physical/sexual experiences and psychological neglect), and PTSD with SA in college students from Northeastern Brazil. As hypothesized, trait impulsivity remained associated with SA even after the insertion of other variables that have been shown to exert an effect on SA. One possible hypothesis is that impulsivity acted longitudinally, ${ }^{10}$ partially mediated by other variables (trauma exposure and PTSD) that, as predicted by the 3ST model, ${ }^{4,5}$ will contribute to suicide capability. Lifetime exposure to traumatic events and PTSD were positively associated with SA, and we found a gradual fall in the high OR of impulsivity as other variables - notably trauma exposure and PTSD - were included in the model. This data seems to be in agreement with authors who also discuss how historical and environmental variables can mediate or change impulsivity, acting as determinant factors for suicidal behavior. ${ }^{15,38}$

For a variable to be considered a distal factor in relation to SAs, its association with SA should be examined through other variables, such as environmental factors, which contribute to higher suicide capability. ${ }^{10}$ Previous research has shown the relation between negative urgency, a facet of impulsivity, and lifetime number of SAs is mediated by participants' lifetime number of painful or provocative events. ${ }^{39}$ In our study, the inclusion of 
Table 3 Multivariate hierarchical analysis of factors associated with suicide attempt in college students in Northeastern Brazil, grouped by levels

\begin{tabular}{|c|c|c|c|c|c|}
\hline Variables & $\begin{array}{c}\text { Model A } \\
\text { (Blocks 1, 2) } \\
\text { OR }(95 \% \mathrm{Cl})\end{array}$ & $\begin{array}{c}\text { Model B } \\
\text { (Blocks 1-4) } \\
\text { OR }(95 \% \mathrm{Cl})\end{array}$ & $\begin{array}{c}\text { Model C } \\
\text { (Blocks 1-5) } \\
\text { OR }(95 \% \mathrm{Cl})\end{array}$ & $\begin{array}{c}\text { Model D } \\
\text { (Blocks 1-6) } \\
\text { OR }(95 \% \mathrm{Cl})\end{array}$ & $\begin{array}{c}\text { Model E } \\
\text { (Blocks 1-7) } \\
\text { OR }(95 \% \mathrm{Cl})\end{array}$ \\
\hline \multicolumn{6}{|c|}{$\begin{array}{l}\text { Level } 1 \text { - Socioeconomic variables } \\
\text { and impulsivity }\end{array}$} \\
\hline \multicolumn{6}{|c|}{ Block 1} \\
\hline \multicolumn{6}{|l|}{ Marital status } \\
\hline Married & 1.00 & 1.00 & 1,00 & 1.00 & 1.00 \\
\hline Single & $1.44(1.03-2.02)$ & $1.41(0.99-1.99)$ & $1.40(0.99-1.99)$ & $1.33(0.93-1.90)$ & $1.36(0.92-2.01)$ \\
\hline \multicolumn{6}{|l|}{ Family income } \\
\hline$D+E$ & 1.00 & 1.00 & 1.00 & 1.00 & 1.00 \\
\hline $\mathrm{C}$ & $0.65(0.42-0.99)$ & $0.67(0.43-1.04)$ & $0.66(0.42-1.04)$ & $0.67(0.42-1.05)$ & $0.66(0.41-1.06)$ \\
\hline$A+B$ & $0.57(0.38-0.86)$ & $0.63(0.41-0.95)$ & $0.67(0.43-1.03)$ & $0.68(0.44-1.05)$ & $0.68(0.43-1.07)$ \\
\hline \multicolumn{6}{|l|}{ Block 2} \\
\hline \multicolumn{6}{|l|}{ Impulsivity } \\
\hline Low & 1.00 & 1.00 & 1.00 & 1.00 & 1.00 \\
\hline Medium & $2.74(1.32-5.69)$ & $2.59(1.24-5.41)$ & $2.58(1.22-5.42)$ & $2.45(1.16-5.17)$ & $2.12(1.00-4.50)$ \\
\hline High & $7.35(3.43-15.76)$ & $6.36(2.94-13.75)$ & $5.89(2.69-12.86)$ & $4.81(2.18-10.60)$ & $4.04(1.82-8.95)$ \\
\hline \multirow{2}{*}{\multicolumn{6}{|c|}{$\begin{array}{l}\text { Level } 2 \text { - Trauma history (age } \leqslant 12 \text { ) } \\
\text { and psychological neglect }\end{array}$}} \\
\hline & & & & & \\
\hline \multicolumn{6}{|c|}{ Block 3} \\
\hline \multicolumn{6}{|c|}{ Physical/sexual experiences } \\
\hline Yes & & $1.76(1.13-2.73)$ & $1.59(1.02-2.49)$ & $1.48(0.94-2.33)$ & $1.46(0.92-2.33)$ \\
\hline No & & 1.00 & 1.00 & 1.00 & 1.00 \\
\hline \multicolumn{6}{|l|}{ Block 4} \\
\hline \multicolumn{6}{|l|}{ Psychological neglect } \\
\hline Yes & & $2.16(1.53-3.05)$ & $2.47(1.57-3.89)$ & $2.18(1.37-4.08)$ & $1.79(1.24-2.58)$ \\
\hline No & & 1.00 & 1.00 & 1.00 & 1.00 \\
\hline \multicolumn{6}{|c|}{ Level 3 - Trauma history (age > 12) } \\
\hline \multicolumn{6}{|c|}{ Block 5} \\
\hline \multicolumn{6}{|c|}{ Physical/sexual experiences } \\
\hline Yes & & & $2.80(1.88-4.19)$ & $2.41(1.60-3.64)$ & $2.39(1.56-3.65)$ \\
\hline No & & & 1.00 & 1.00 & 1.00 \\
\hline \multirow{2}{*}{\multicolumn{6}{|c|}{$\begin{array}{l}\text { Level } 4 \text { - Post-traumatic stress disorder } \\
\text { and druq use }\end{array}$}} \\
\hline & & & & & \\
\hline \multicolumn{6}{|c|}{ Block 6} \\
\hline \multicolumn{6}{|l|}{ PTSD } \\
\hline Yes & & & & $2.80(1.92-4.08)$ & $2.69(1.82-3.96)$ \\
\hline No & & & & 1.00 & 1.00 \\
\hline \multicolumn{6}{|l|}{ Block 7} \\
\hline \multicolumn{6}{|l|}{ Drug use } \\
\hline Never & & & & & 1.00 \\
\hline One drug & & & & & $1.34(0.89-1.99)$ \\
\hline Two or more drugs & & & & & $1.68(0.97-2.89)$ \\
\hline \multicolumn{6}{|l|}{ Potential confounders } \\
\hline \multicolumn{6}{|l|}{ Sex } \\
\hline Female & & & & & 1.00 \\
\hline Male & & & & & $0.59(0.38-0.90)$ \\
\hline \multicolumn{6}{|l|}{ Age, years } \\
\hline$\leqslant 22$ & & & & & 1.00 \\
\hline$e>22$ & & & & & $0.90(0.61-1.34)$ \\
\hline
\end{tabular}

Akaike information criterion (AIC): level $1=1,085$; level $2=1,061$; level $3=1,035$; level $4=1,005$.

$95 \% \mathrm{Cl}=95 \%$ confidence interval; OR = odds ratio; PTSD = post-traumatic stress disorder.

factors associated with higher suicide capability, such as PTSD and trauma history, reduced the association of impulsivity with SAs, suggesting a mediation effect for these factors that is in accordance with a distal role for impulsivity. One hypothesis to explain the role of impulsivity as a longitudinal factor is that clinical and nonclinical samples will act differently given higher levels of impulsivity. Nonclinical samples may engage in impulsive behaviors that are not provocative or painful enough to directly affect their acquired capability, whereas clinical samples may engage in riskier, more provocative events that are more likely to increase their suicide capability. ${ }^{39,40}$

With regard to painful and provocative events, our findings indicate that physical/sexual traumatic experiences after 12 years old and psychological neglect increased the likelihood of SA. In our analysis, however, there was no association between trauma history before 
12 years old and SA - an interesting finding, given the available evidence showing that childhood trauma is associated with suicidal behavior. ${ }^{13,41,42}$ Considering the vulnerability in these early stages of life, a possible hypothesis that explains this finding is the eminent association between early trauma exposure and PTSD. This could mean that these variables are actually reflecting similar aspects of the same phenomenon; adding the PTSD variable later in the model could lower the predictive value of the earlier trauma exposure factor. Therefore, it may be clinically relevant to focus on traumatic experiences that are contemporaneous to one's current suicidal behavior, rather than those experiences that happened earlier in one's childhood.

PTSD is included as the latter variable in the hierarchical model and was associated with an increased likelihood of SA. This finding of an association between PTSD and SA is in accordance with a Brazilian crosssectional study which showed a high prevalence of suicide risk in subjects with PTSD. ${ }^{43}$ It agrees with two other studies that assessed a large number of participants: a cohort ${ }^{44}$ which found that PTSD was a predictor of subsequent $S A$ in young adults, and the other by Nock et al., ${ }^{21}$ who reported an association between PTSD and $S A$. In line with these results, previous work found that PTSD symptoms were associated with SI and behavior among university students, and pointed to a mediating role of perceived distress tolerance (i.e., the capacity to withstand aversive or negative emotional states). This means that PTSD symptom severity exerted an indirect effect on suicide risk through self-reported, perceived distress tolerance. ${ }^{45}$ This indirect effect may be assessed by future studies that investigate the involvement of psychological factors and their association with SA.

Our findings should be interpreted in light of some limitations. The cross-sectional design of the study precludes conclusions about the causality of the relationship between impulsivity, trauma exposure, and SA. Another consequence of the cross-sectional design is its impact on how well our model can capture past events as they are recalled some or many years later by the study participants, which can alter the impact of these variables in the model due to recall bias. All measures were selfreported, which could inflate effect sizes. Memory bias in the assessment of a previous traumatic experience and drug use must be considered. Recall biases can affect subjective measurements of substance use, resulting in underreporting of drug and alcohol consumption and frequency thereof; ${ }^{46,47}$ therefore, the predictive value of drug use variable in the model may have decreased. Other mental disorders besides PTSD (e.g., depression, bipolar disorder, schizophrenia), which are highly associated with suicidality and could act as a confounder in our analysis by increasing SA and symptom severity, were not investigated. Our sample was selected for reasons of convenience; it is not representative of the population as a whole and, indeed, may misrepresent it. Lastly, we only evaluated first- and last-semester college students during class time, which may have excluded subjects with more severe mental disorders or substance use disorders who might be missing classes due to disability. Despite these limitations, the results of the present study are strengthened by its large sample of young college students, a population generally reported as having high rates of suicide risk. ${ }^{1}$

Our results suggest that trait impulsivity may be interpreted as exerting a longitudinal effect on SA, even in the presence of other variables - such as history of trauma, psychological neglect, and PTSD - which also increase the odds of SA. One hypothesis is that impulsivity may be related to an increased likelihood of exposure to traumatic events, leading to PTSD occurrence. Early intervention on trait impulsivity and adverse environmental conditions might be two primary prevention strategies for SA. These findings also reinforce the importance of treating PTSD as early as possible as a means of reducing the likelihood of SAs.

\section{Acknowledgements}

This work was supported by the Edital Universal Ministério da Ciência e Tecnologia (MCT)/Conselho Nacional de Desenvolvimento Científico e Tecnológico (CNPq; grant number 474869/2010-5, 14/2010). The funders had no role in study design, preparation of the manuscript or decision to publish. FV and BS-M are funded by Coordenação de Aperfeiçoamento de Pessoal de Nível Superior (CAPES) scholarships.

The authors would like to thank all the participants who agreed to be included in this study for their cooperation. We are also grateful to the Trauma and Anxiety Disorders Study Group/Universidade Federal da Bahia: Adriana Duarte, Albaniza Formiga, Amanda Loureiro, Antonio Dantas, Deivson Mundim, Fernanda Dias, Fransuélio Nascimento, Isabela Albuquerque, Jesana Damasceno, José Rômulo Nogueira, Lilian Carvalho, Maria RosaDantas, Perla Soares, Rana Barbosa, Reinilza Nunes, Susan Carvalho, and Weslley Batista. We also thank Dr. Marie-Claude Geoffroy for suggestions and critical revision of the manuscript, and Mônica and Rubens Lima for their technical assistance.

\section{Disclosure}

FK reports personal fees from Daiichi Sankyo and Janssen-Cilag. ALTL reports grants and personal fees from Janssen Pharmaceutical; personal fees from Daiichi Sankyo, Cristalia Produtos Químicos e Farmacêuticos, Libbs, Pfizer, Myralis Pharma, Aché Laboratórios, Hypera Pharma, and Sanofi-Aventis; and grants from Eli Lilly, H. Lundbeck A/S, Servier Laboratories, Hoffman-La Roche, Forum Pharmaceuticals, and from two public funding agencies, CNPq and FAPESP. LCQ reports consulting fees from Allergan, Abbot, Janssen Pharmaceutical, and Lundbeck, and research fees from Janssen Pharmaceutical. The other authors report no conflicts of interest.

\section{References}

1 Naghavi M. Global, regional, and national burden of suicide mortality 1990 to 2016: systematic analysis for the Global Burden of Disease Study 2016. BMJ. 2019;364:194. 
2 Machado CD, Ballester PL, Cao B, Mwangi B, Caldieraro MA, Kapczinski $F$, et al. Prediction of suicide attempts in a prospective cohort study with a nationally representative sample of the US population. Psychol Med. 2021 Jan 14; 1-12. doi: 10.1017/S0033291 720004997. Online ahead of print.

3 Klonsky ED, Saffer BY, Bryan CJ. Ideation-to-action theories of suicide: a conceptual and empirical update. Curr Opin Psychol. 2018;22:38-43.

4 Klonsky ED, May AM. The three-step theory (3ST): a new theory of suicide rooted in the "ideation-to-action" framework. Int J Cogn Ther. 2015;8:114-29.

5 Klonsky ED, Pachkowski MC, Shahnaz A, May AM. The three-step theory of suicide: description, evidence, and some useful points of clarification. Prev Med. 2021;152:106549.

6 Center for Substance Abuse Treatment. Addressing suicidal thoughts and behaviors in substance abuse treatment. treatment improvement Protocol (TIP) series, No. 50. Rockville: Substance Abuse and Mental Health Services Administration; 2009.

7 Goldbloom DS, Davine J. Psychiatry in primary care. a concise Canadian pocket guide. 2nd ed. 2019.

8 Klonsky ED, May A. Rethinking impulsivity in suicide. Suicide Life Threat Behav. 2010;40:612-9.

9 Klonsky ED, May AM. Impulsivity and suicide risk: review and clinical implications. Psychiatr Times. 2015;32:13-20.

10 Anestis MD, Soberay KA, Gutierrez PM, Hernández TD, Joiner TE. Reconsidering the link between impulsivity and suicidal behavior. Pers Soc Psychol Rev. 2014;18:366-86.

11 Dhingra K, Klonsky ED, Tapola V. An empirical test of the three-step theory of suicide in U.K. university students. Suicide Life Threat Behav. 2019;49:478-87

12 Van Orden KA, Witte TK, Cukrowicz KC, Braithwaite SR, Selby EA, Joiner TE Jr. The interpersonal theory of suicide. Psychol Rev. 2010;117:575-600.

13 Zatti C, Rosa V, Barros A, Valdivia L, Calegaro VC, Freitas LH, et al. Childhood trauma and suicide attempt: a meta-analysis of longitudinal studies from the last decade. Psychiatry Res. 2017;256:3538.

14 Dube SR, Anda RF, Felitti VJ, Chapman DP, Williamson DF, Giles WH. Childhood abuse, household dysfunction, and the risk of attempted suicide throughout the life span: findings from the adverse childhood experiences study. JAMA. 2001;286:3089-96.

15 Brodsky BS, Oquendo M, Ellis SP, Haas GL, Malone KM, Mann JJ. The relationship of childhood abuse to impulsivity and suicidal behavior in adults with major depression. Am $J$ Psychiatry. 2001;158:1871-7.

16 Ryan AT, Daruwala SE, Perera KU, Lee-Tauler SY, Tucker J, Grammer $\mathrm{G}$, et al. The relationship between trauma exposure and psychiatric hospitalization for suicide ideation or suicide attempt among patients admitted to a military treatment setting. Int J Environ Res Public Health. 2020;17:2729.

17 Christensen H, Batterham PJ, Mackinnon AJ, Donker T, Soubelet A. Predictors of the risk factors for suicide identified by the interpersonal-psychological theory of suicidal behaviour. Psychiatry Res. 2014;219:290-7.

18 Li W, Dorstyn DS, Jarmon E. Identifying suicide risk among college students: a systematic review. Death Stud. 2020;44:450-8.

19 Bryan C, Anestis M. Reexperiencing symptoms and the interpersonal-psychological theory of suicidal behavior among deployed service members evaluated for traumatic brain injury. J Clin Psychol. 2011;67:856-65

20 Silva C, Ribeiro JD, Joiner TE. Mental disorders and thwarted belongingness, perceived burdensomeness, and acquired capability for suicide. Psychiatry Res. 2015;226:316-27.

21 Nock M, Hwang I, Sampson NA, Kessler RC. Mental disorders, comorbidity and suicidal behavior: results from the National Comorbidity Survey Replication. Mol Psychiatry. 2010;15:868-76.

22 Jordan JT, Samuelson KW, Tiet QQ. Impulsivity, painful and provocative events, and suicide intent: testing the interpersonal theory of suicide. Suicide Life Threat Behav. 2019;49:1187-95.

23 Associação Nacional dos Dirigentes das Instituições Federais de Ensino Superior, Fórum Nacional de Pró-Reitores de Assuntos Estudantis. V Pesquisa Nacional de Perfil Socioeconômico e Cultural dos(as) Graduandos(as) das IFES 2018 [Internet]. 2019 [cited 2021 nov 17]. www.fonaprace.andifes.org.br/site/wp-content/uploads/2019/
06/V-Pesquisa-do-Perfil-Socioecono\%CC\%82mico-dos-Estudantesde-Graduac\%CC\%A7a\%CC\%83o-das-U.pdf

24 Cerqueira D, de Lima RS, Bueno S, Palmieri Alves P, Reis M, Cypriano $\mathrm{O}$, et al. Atlas da violência: retratos dos municípios brasileiros [Internet]. 2019 [cited 2021 Nov 17]. www.ipea.gov.br/ portal/images/stories/PDFs/relatorio_institucional/190802_atlas_da_ violencia_2019_municipios.pdf

25 Brasil, Instituto Nacional de Estudos e Pesquisas Educacionais Anísio Teixeira (INEP), Ministério da Educação (MEC). Resumo Técnico do Censo da Educação Superior 2019 [Internet]. 2021 [cited 2021 Nov 17]. download.inep.gov.br/publicacoes/institucionais/esta tisticas_e_indicadores/resumo_tecnico_censo_da_educacao_super ior_2019.pdf

26 Azevedo M, Guerra V. Infância e violência fatal em família: primeiras aproximações ao nível de Brasil. São Paulo: Iglu; 1998.

27 Fiszman A, Cabizuca M, Lanfredi C, Figueira I. The crosscultural adaptation to Portuguese of the trauma history questionnaire to identify traumatic experiences. Braz J Psychiatry. 2005;27:63-6.

28 Berger W, Mendlowicz MV, Souza WF, Figueira I. Equivalência semântica da versão em português da Post-Traumatic Stress Disorder Checklist - Civilian Version (PCL-C) para rastreamento do transtorno de estresse pós-traumático. Rev Psiquiatr Rio Gd Sul. 2004;26:16775.

29 American Psychiatric Association. Diagnostic and Statistical Manual of Mental Disorders, Fourth Edition, Text Revision (DSM-IV-TR) Arlington: American Psychiatric Publishing; 2000.

30 Adkins JW, Weathers FW, McDevitt-Murphy M, Daniels JB. Psychometric properties of seven self-report measures of posttraumatic stress disorder in college students with mixed civilian trauma exposure. J Anxiety Disord. 2008;22:1393-402.

31 Netto LR, Cavalcanti-Ribeiro P, Pereira JL, Nogueira JF, Santos LL, Lira SB, et al. Clinical and socio-demographic characteristics of college students exposed to traumatic experiences: a census of seven college institutions in Northeastern Brazil. PLoS One. 2013;8: e78677.

32 von Diemen L, Szobot CM, Kessler F, Pechansky F. Adaptation and construct validation of the Barratt Impulsiveness Scale (BIS 11) to Brazilian Portuguese for use in adolescents. Braz J Psychiatry. 2007;29:153-6.

33 Kehle-Forbes SM, Chen S, Polusny MA, Lynch KG, Koffel E, Ingram $\mathrm{E}$, et al. A randomized controlled trial evaluating integrated versus phased application of evidence-based psychotherapies for military veterans with comorbid PTSD and substance use disorders. Drug Alcohol Depend. 2019;205:107647.

34 Santos DN, Assis AM, Bastos AC, Santos LM, Santos CA, Strina A, et al. Determinants of cognitive function in childhood: a cohort study in a middle income context. BMC Public Health. 2008;8:202.

35 Victora CG, Huttly SR, Fuchs SC, Olinto MT. The role of conceptual frameworks in epidemiological analysis: a hierarchical approach. Int J Epidemiol. 1997;26:224-7.

36 Mohi S, Deane FP, Mooney-Reh D, Bailey A, Ciaglia D. Experiential avoidance and depression predict values engagement among people in treatment for borderline personality disorder. J Context Behav Sci. 2021;20:94-100.

37 Lewis M. Stepwise versus hierarchical regression: pros and cons. In: Annual meeting of the Southwest Educational Research Association; 2007; San Antonio, EUA. files.eric.ed.gov/fulltext/ED534385.pdf

38 Oquendo MA, Friend JM, Halberstam B, Brodsky BS, Burke AK, Grunebaum MF, et al. Association of comorbid posttraumatic stress disorder and major depression with greater risk for suicidal behavior. Am J Psychiatry. 2003;160:580-2.

39 Anestis MD, Fink EL, Bender TW, Selby EA, Smith AR, Witte TK, et al. Re-considering the association between negative urgency and suicidality: negative urgency and suicide. Personal Ment Health. 2012;6:138-46.

40 Bender TW, Gordon KH, Bresin K, Joiner TE Jr. Impulsivity and suicidality: the mediating role of painful and provocative experiences. J Affect Disord. 2011;129:301-7.

41 Angelakis I, Gillespie EL, Panagioti M. Childhood maltreatment and adult suicidality: a comprehensive systematic review with metaanalysis. Psychol Med. 2019;49:1057-78.

42 Lopez-Castroman J, Jaussent I, Beziat S, Guillaume S, Baca-Garcia $E$, Olié E, et al. Posttraumatic stress disorder following childhood 
abuse increases the severity of suicide attempts. J Affect Disord. 2015;170:7-14.

43 Bach SL, Molina MA, Jansen K, da Silva RA, Souza LD. Suicide risk and childhood trauma in individuals diagnosed with posttraumatic stress disorder. Trends Psychiatry Psychother. 2018;40: 253-7.

44 Wilcox HC, Storr CL, Breslau N. Posttraumatic stress disorder and suicide attempts in a community sample of urban American young adults. Arch Gen Psychiatry. 2009;66:305-11.
45 Kratovic L, Smith LJ, Vujanovic AA. PTSD symptoms, suicidal ideation, and suicide risk in university students: the role of distress tolerance. J Aggress Maltreat Trauma. 2021;30:82-100.

46 Gmel G, Daeppen JB. Recall bias for seven-day recall measurement of alcohol consumption among emergency department patients: implications for case-crossover designs. J Stud Alcohol Drugs. 2007;68:303-10.

47 Johnson T, Fendrich M. Modeling sources of self-report bias in a survey of drug use epidemiology. Ann Epidemiol. 2005;15:3810-9. 